\title{
Democracia política y democracia social en América Latina
}

Carlos M. Vilas

CIIH-UNAM

E

1 reconocimiento de la existencia de una relación estrecha entre regímenes políticos y estructuras socioeconómicas data desde los orígenes mismos de la ciencia política. Fue Aristóteles quien explicitó y sistematizó por vez primera la estrecha imbricación de economía política, el condicionamiento de ésta por aquélla y la necesaria adecuación dé los diversos regímenes políticos a las formas de producción y a la estructura social. La politeia, es decir la constitución real o régimen político, es para Aristóteles

la ordenación de los poderes gubernativos de una comunidad soberana, de cómo están distribuidas las funciones de tales poderes, de cuál es el grupo so- cial dominante en la comunidad, $y$ de cuál es el fin asignado a la comunidad por ese grupo dominante. ${ }^{1}$

En el lenguaje de las ciencias sociales modernas diremos, pues, que Aristóteles afirma que el régimen político es expresión de la estructura social existente; es decir, en una sociedad capitalista, de su estructura de clases y, a través de ésta, de su estructura económica, ya que la diferenciación de la sociedad en clases toma cuerpo a

1 Aristóteles, Politica (según ta traducción de Arturo Sampay), 1958, 1289a, pp. 15-18; pp. $60-61$. 


\section{SECUENCIA}

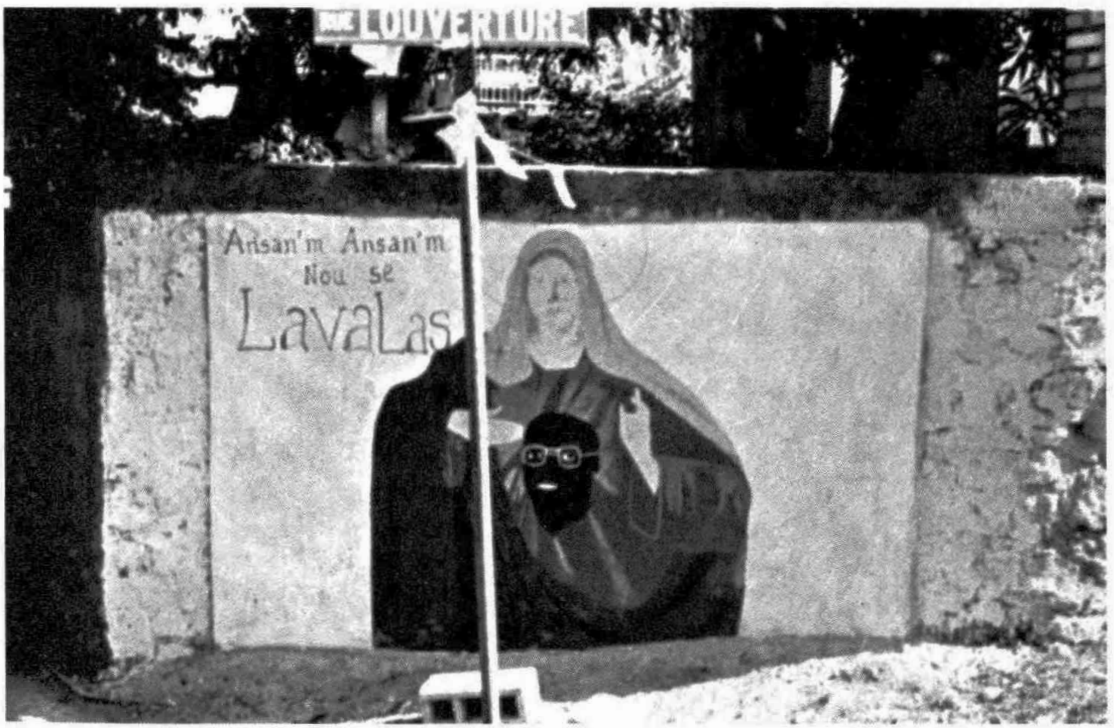

partir del modo de incorporarse los colectivos de individuos a las relaciones de producción y reproducción.

Para Aristóteles la diversidad de regímenes políticos se explica por la diversidad de grupos sociales, por los antagonismos que los oponen entre sí y por la dominación de unos sobre otros. ${ }^{2}$ Siendo solamente dos los grupos sociales principales: el de los ricos y el de los pobres, ${ }^{3}$ también sólo dos son los regímenes políticos: la oligarquía y la democracia, respectivamente. ${ }^{4}$

La percepción de esta relación estrecha entre política y sociedad si-

2 Ibid., 1289 b, pp. $27-28$ y 1290 a, pp. 5-12.

3 Ibid., 1291 b, pp. 5-10.

${ }^{4}$ Ibid., 121 b, pp. 10-13 y 1301b, pp. 38-40. guió vigente hasta el origen de los tiempos contemporáneos. Así, en el proceso de formación del Estado moderno el concepto de ciudadano, como sujeto político de este Estado, se constituyó a partir de la propiedad de medios de producción. En una época en que la burguesía no recurría a circunloquios, Adam Smith fue particularmente explícito:

En la medida en que el Estado ha sido instituido para la defensa de la propiedad, ha sido instituido en realidad para la defensa del rico contra el pobre, de los que tienen alguna propiedad contra los que no la tienen. 5

5 "Civil government, so fair it is instituted for the security of property, it is in reality instituted 
Medio siglo más tarde, Thomas Cooper, humanista, jeffersoniano entusiasta y uno de los hombres más cultos de su tiempo, afirmaba:

La sociedad ha sido establecida para la protección de la propiedad; las disputas en torno a la propiedad le dicron natural nacimiento. ¿Qué derecho tazonable pueden tener los que carecen de propiedad para legislar sobre la propiedad de otros? ¿Qué motivo o interćs común existe entre estas dos categorías de habitantes? ${ }^{6}$

Esta rapidísima incursión en dos de los voceros más lúcidos de una clase en ascenso es apenas una muestra de la tendencia predominante en el pensamiento burgués de la época. Su contraste con las democracias capitalistas del siglo $\mathrm{xx}$ demuestra que lo que se conoce como democracia burguesa (sufragio universal, derecho a la libre asociación, jornada taboral limitada, etc.) es más el producto de la lucha de los trabajadores, y de los pobres en general, hombres y mujeres, por obtener el reconocimiento de sus derechos, que la aplicación de las formulaciones teóricas clasistas originales. ${ }^{7}$

for the defense of the rich against the poor. of those who have some property against those who have none at all." Smith, Inquiry, 1976. t. II, p. 236.

6 "Society was instituted for the protection of property; quarrels about property would naturally give rise to it. What reasonable claim can they have, who have no property of their own, to legislate on the property of others? What common motive and common interest is there between these two prescriptions of inhabitants?" Cooper, Lectures, 1829, p. 363.

7 Therborn, "The rule of capital", pp. 71-109, y Przeworski, Capitalismo y social democracia.
Lo que se conoce convencionalmente como democracia burguesa debe, por lo tanto, mucho más a las presiones populares que a la benevolencia o a las convicciones filosóficas de los de arriba.

En América Latina se registra una situación similar. Por encima de ideologias y banderas partidarias específicas, una de las constantes más fuertes de la historia política del continente es esa vinculación de la democratización institucional con el desarrollo de ciertas transformaciones socioeconómicas básicas. Trátese del movimiento independentista o de la generación liberal del siglo pasado; del nacionalismo revolucionario o de los movimientos populistas de masas; de la revolución mexicana, del castrismo o del sandinismo; las expresiones más claras de las clases na. cionales y populares latinoamericanas siempre han visto la democratización en primer lugar como un proceso de desarrollo progresivo, antes que como un conjunto fijo, dado de una vez y para siempre, de instituciones formales; y en segundo lugar, como un proceso de múltiples dimensiones estrechamente interrelacionadas: lo político sin duda, pero también lo socioeconómico; las relaciones entre grupos étnicos, de género y generacionales.

Las preocupaciones populares por la democracia revelan así un sentimiento de insatisfacción con el orden de cosas existentes. De ahí, por lo tanto, las proyecciones inexcusablemente reformistas -es decir, de aspiración al cambio social- de la democracia en nuestra región. Si la política es el ámbito en que la sociedad ex- 
presa y dirime sus conflictos, la democracia es el ámbito en que las clases y grupos populares, de género, étnicos, generacionales, expresan y procesan sus contradicciones y tensiones con el orden social e institucional vigentes.

\section{II}

El desarrollo del pensamiento y de la práctica popular democrática han sido desiguales. La noción liberal del ciudadano libre de toda preocupación que no sea el bien común, que se desprende al emitir su voto, de sus identidades de clase, étnicas, de género, generacionales, regionales, comunitarias, etc., para mejor expresar la voluntad general, tiene su homólogo en la noción económica del "productor libre": un individuo "liberado" de vinculaciones específicas con los medios de producción, pero también con la miriada de determinaciones concretas que configuran la vida real, efectiva, de ese productor. Las organizaciones populares atacaron tempranamente el enmascaramiento clasista que esas concepciones involucraban; el ciudadano abstracto, como el productor libre igualmente abstracto, podían pertenecer a diferentes clases sociales y ubicarse por lo tanto en terrenos opuestos con relación a la explotación social; las condiciones para el ejercicio de las libertades políticas y para la participación institucional, el arco de opciones efectivamente abierto, son diferentes para los ciudadanos ubicados en diferentes clases: para los ricos y para los pobres, para los explotadores y para los explotados.
Esta rápida sensibilización respecto de la desigual ubicación de la gente en la estructura socioeconómica y laboral contrasta con una incorporación más tardía de la problemática de la democratización al terreno de otras identidades sociales que no son estrictamente socioeconómicas, aunque alcancen expresiones en ese terreno: el género y la etnicidad, sobre todo. La proyección del proceso de democratización de la esfera política institucional a la esfera de la producción, la circulación, el consumo, tuvo lugar mucho antes que su proyección al terreno de las relaciones y jerarquizaciones entre hombres y mujeres, y entre grupos étnicos. ${ }^{8}$

La priorización de la crítica teórica y práctica a las desigualdades socioeconómicas por su papel en la generación de desigualdades políticas abonó el desarrollo de la organización sindical, de la legislación social, de la ampliación de los servicios de salud, de educación y la extensión de los derechos de ciudadanía. Pero también condujo a soslayar el cuestionamiento de los otros criterios de desigualdad y opresión, consolidando dentro de la clase la primacía de los elementos que sustentan su dominación en esos otros criterios. Más aún, la limitación durante largo tiempo de la problemática de la democratización al ámbito público o, más exactamente, la aceptación de los términos dominantes de la separación entre lo público y lo privado, neutralizó o desnaturalizó los esfuerzos por llevar la demo-

${ }^{8}$ Cerroni, I/ rapporto, y Miliband, Divided societies. 
cratización a estos otros ámbitos de la jerarquización social. En la medida en que existen desigualdades que se generan en el terreno de lo convencionalmente privado, y lo privado queda al margen de la política y de la producción mercantil -por lo tanto, al margen de la democratización-, los alcances de la democratización se reducen en términos efectivos.

El mantenimiento de las desigualdades y las opresiones "privadas" atenta contra la igualdad y las libertades "públicas". Desconocer la existencia de una dimensión aún no resuelta de esta vasta problemática sería tan necio como restar valor a los avances experimentados en la esfera pública. Pero un proceso de democratización efectiva no puede reducirse al carácter de clase de la dominación. En la América Latina contemporánea, el Estado expresa sin duda, una dominación de clase, pero también resume una dominación de género y, en muchas sociedades, una jerarquización étnica. Es a un mismo tiempo, aunque no siempre en igual medida, un Estado clasista, un Estado etnocéntrico y un Estado androcéntrico. El proceso de democratización debe dirigirse a desbloquear todas las dimensiones de la identidad social, individual y colectiva.

III

La coyuntura que se presenta a los procesos de democratización en América Latina a principios de la década presente es por demás compleja. Se registra, por un lado, un avance notorio de los procesos de democra- tización electoral; por el otro, la profundización y ampliación de una crisis económica con impacto brutal sobre los sectores populares y medios, y que se ensaña sobre todo con las poblaciones rurales, con las mujeres y niños, con los asalariados y con las minorías étnicas. Una democracia electoral circunscrita, ante todo, a lo público político, que debe coexistir con 183000000 de pobres y una epidemia continental de cólera.

La situación es delicada. El proceso de democratización electoral que se desenvolvió en la década de 1980 fue impulsado por las luchas sociales y políticas de un amplio espectro de actores, pero también por el estallido de la crisis de la deuda y por la incapacidad de los regímenes militares y los grupos dominantes, para manejarla. E1 recurso a elecciones puede ser interpretado como un resultado tanto de las movilizaciones populares y ciudadanas como de la decisión militar de dar un paso al costado. La crisis de la deuda abonó el terreno de las llamadas transiciones democráticas, pero al mismo tiempo limitó el alcance y la profundidad de ellas, y hoy enmarca con múltiples interrogantes la solidez de esos procesos, su contenido efectivo y su futuro. La incapacidad -para no juzgar las intenciones- de los así surgidos para alcanzar una mínima solución a los problemas más urgentes de la gente y mejorar las condiciones de negociación externa, echan un manto de sombra sobre la efectiva consolidación de los procesos de democratización en la región.

- Uno de los aspectos más llamativos de esta conjugación de crisis pro- 
funda y extendida, con procesos electorales, es el retroceso de una óptica reformista en los gobiernos latinoamericanos y en buena parte de los in. telectuales. Hablando en términos generales, hay que admitir que el reemplazo de los regímenes dictatoriales no involucró una recuperación del pensamiento social que enfatizaba la necesidad de introducir reformas profundas en la estructura de nuestras sociedades para alcanzar desarrollo, democracia y equidad. Al contrario, después de una década de represión, persecuciones y censura, la abdicación de lo que algunà vez se llamó "pen. samiento crítico" latinoamericano es apabullante. Más aún, la crisis del Este ha sido utilizada por muchos para dar la espalda no sólo a los aportes del marxismo al conocimiento de la realidad latinoamericana, sino también a los productos de los debates de las décadas anteriores y de sus contribuciones a un mejor conocimiento de nuestra realidad: se hace mofa de la teoría leninista del imperialismo, pero también tiran a la basura los aportes de Raúl Prebisch, que nada tienen que ver con aquélla.

El espíritu reformista ha desaparecido de los gobiernos latinoamericanos; los intentos del pasado de regular el mercado para conjugar democracia con desarrollo y equidad son reproba. dos hoy y se les responsabiliza de los males actuales. Apoyados en las movilizaciones de las masas y los grupos medios, los regímenes electorales reproducen sin embargo la óptica de las elites dominantes. Es innegable que las urgencias de corto plazo que plantea la crisis económica no dejan es- pacio para proyectos de reformas que apuntan a la configuración estructural de nuestras sociedades, pero esto no debería soslayar la evidencia de que, de todos modos, la forma en que la crisis se encara no es políticamente neutra, y que existen pequeños grupos, tradicionalmente poderosos, que han sabido sacar ganancias de la crisis y de las medidas aplicadas a su respecto.

La circunstancia de que estas políticas sean ejecutadas por gobiernos surgidos de elecciones pone a estos procesos de democratización en aprietos. Por un lado, las protestas populares, muchas de ellas de violencia extrema, indican que no es esto en lo que están pensando los electores cuando concurren a las urnas. Por otro lado, los intentos de mejorar la imagen de estas políticas, apelando al caracter cívicamente electo de los gobiernos que las promueven, choca contra la evidencia de la ira popular. Es innegable el sentimiento de burla y de engaño de la gente: una situación que contribuye poco a la consolidación de las instituciones democráticas.

\section{IV}

La cuestión de la democracia social en América Latina mantiene su actualidad -aunque no fuere por otras razonespor la renovada ineficacia de los enfoques meramente institucionales de la democracia de hacerse cargo de los problemas fundamentales de la gente, empezando por los problemas básicos de comida, trabajo, educación $y$ salud.

Ahora bien: estas limitaciones no 
son obstáculo para reconocer que esos procesos de democratización restringida definen un marco institucional determinado. En el pasado, tendió a reducirse el contenido y alcances de los proyectos políticos populares a las vías y estrategias de lucha que se adoptaran y, en particular, a exaltarse a la lucha no institucional, de preferencia armada, casi como sinónimo de proyecto popular. Al reducir la problemática revolucionaria a la cuestión del método de la lucha política, las izquierdas latinoamericanas reprodujeron el sesgo de las derechas, que reducen la problemática de la democracia al método electoral.

La opción por determinadas formas de lucha depende de un conjunto amplio de factores, entre los que la voluntad de los actores es sólo uno. La convocatoria revolucionaria prende en las masas en respuesta a situaciones en las que los canales institucionales se encuentran cerrados explícita o implícitamente: dictaduras abiertas, fraude o manipulación electoral, represión de la oposición popular, entre otros. En estas situaciones, el elemento que tiende a movilizar a la población suele ser más el contenido democratizador de la lucha que las transformaciones socioeconómicas en sí mismas. En todo caso, el acceso a condiciones de vida más dignas aparece ligado, en la conciencia colectiva, a la eliminación de la represión y a la transformación de las relaciones e instituciones políticas.

El apoyo reciente del gobierno de Estados Unidos y de los grupos dominantes de América Latina a los procesos electorales expresa el reconoci- miento de que en la raíz de la aceptación popular de la convocatoria revolucionaria se encontraba una reivindicación democrática insoslayable.

El desenvolvimiento de las luchas populares por transformaciones sociales, y la profundización de la democracia en el marco de las instituciones políticas constitucionales, incrementa su contenido explícitamente político. El paradigma heredado de la revolución francesa -continuado por las revoluciones rusa y cubana- de unos enemigos de clase que ceden el terreno y salen del país o son sometidos a la justicia revolucionaria, no funciona. El enemigo de clase se queda, y lucha por conservar sus posiciones institucionales y bloquear el avance del proyecto popular. Es una situación que recuerda claramente a la de la Unidad Popular en Chile y también, de alguna manera, a la del sandinismo en Nicaragua. Las instituciones, los aparatos del Estado, se convierten en otras tantas trincheras en disputa. Ia imagen de la guerra de posiciones de Gramsci es inexcusable.

iSignifica esto que se trata de un proceso más lento? Si por democracia social y económica se entiende estatización de la sociedad y la economía, es claro que la vía del asalto armado al poder resulta mucho más rápicla. Pero es, ante todo, una vía que depende de un conjunto amplio y completo de condiciones y no sólo de la voluntad de los actores sociales, y cuyos resultados son impredecibles. No por azar los procesos revolucionarios constituyen momentos excepcionales en la historia. Una revolución es algo en lo que la gente se mete cuando no ve otra al- 
ternativa para mejorar sus condiciones de vida y recuperar un sentimiento de dignidad, o para defender to poco de lo que aún no ha sido ilegítimamente privada.

Por otro lado, lo que no se revolucionariza antes desde la sociedad, debe revolucionarse después desde el Estado, y éste es un proceso de desenvolvimiento prolongado, en la medida que implica transformar hábitos y estilos profundamente arraigados en la mente y en el corazón de la gente. La contradicción entre los tiempos del Estado y los de la sociedad se hace manifiesta, y se agudiza por las presiones externas; la desarticulación de las viejas instituciones tienen lugar más rápido que la creación de las nuevas; viejas prácticas y estilos se mimetizan y reproducen debajo de las nuevas formas; la cultura cambia más lentamente, y más en el largo plazo, que las leyes y los decretos. La idea de que por definición una sociedad avanza más rápido por la vía revolucionaria debería examinarse, por lo tanto, a la luz de experiencias específicas.

El panorama político que se representa hoy en América Latina enfatiza la necesidad de una estrategia popular de lucha institucional y por las instituciones. El terreno institucional no es políticamente neutro; el Estado tiene un contenido y un sentido de clase, y además expresa y reproduce relaciones de subordinación externa. Pero solamente el agotamiento de los espa-

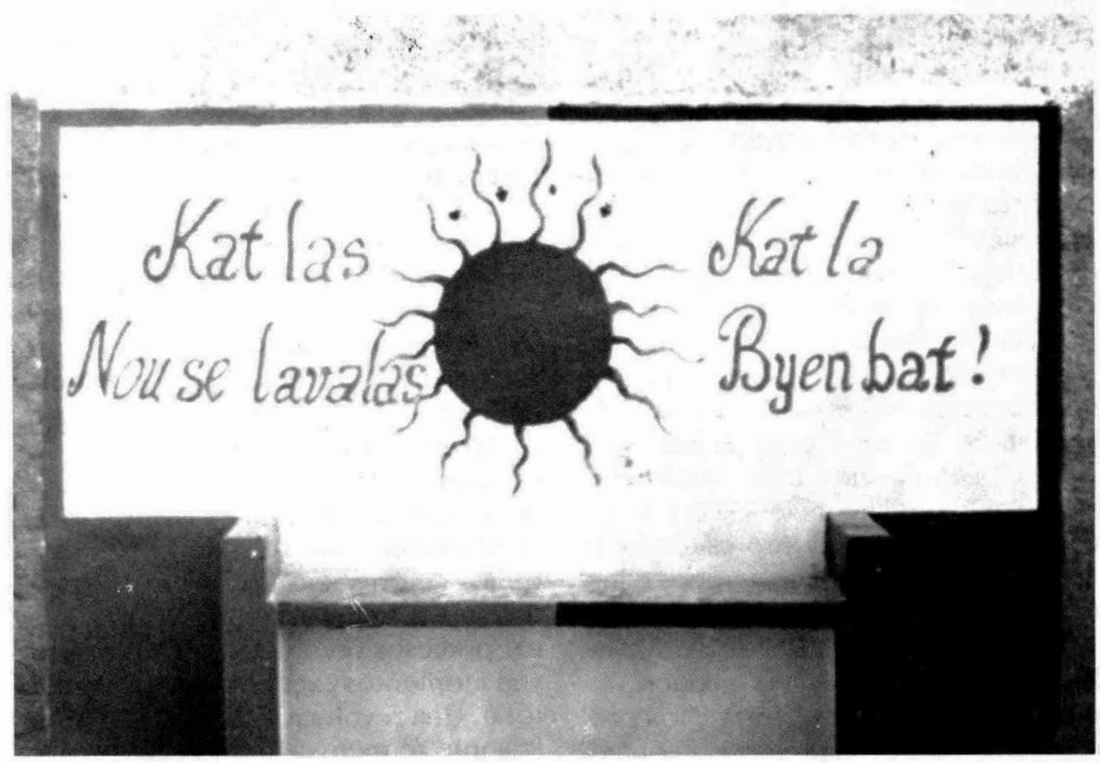


cios institucionales legitima ante la población el recurso a otras formas de acción.

La renovación del pensamiento crítico latinoamericano, impulsada por los procesos revolucionarios centroamericanos y por el auge de los llamados "nuevos movimientos sociales" en América del Sur, permitió avanzar sobre las limitaciones que derivaban de un enfoque predominantemente socioeconómico del campo popular, e identificar un espectro amplio de sujetos sociales en los procesos de transformación. En algunos casos la afirmación de que la clase no agota la identidad de los sujetos fue entendida como significación de que la identidad de clase es irrelevante en la formación de los comportamientos colectivos; en otras ocasiones el relevamiento de los "nuevos movimientos" no prestó atención a los elementos de continuidad, en nuevos contextos, que existen entre éstos y formas anteriores de movilización y protesta política popular. Sea como fuere, es innegable que las perspectivas que el pensamiento crítico latinoamericano tiene hoy del campo popular son más amplias, y sin dudas más acertadas, que las del pasado reciente.

\section{V}

La magnitud de la crisis ha convertido a la economía en el centro de la problemática actual. Paradójicamente, es en este punto donde más vulnerable es el pensamiento crítico latinoamericano. La afirmación trivial de que no existen alternativas a las políticas de ajuste, formulada por no pocos diri- gentes e intelectuales del campo popular, es la mejor prueba de ello. Es la debilidad del campo popular la que explica el recurso a políticas de ajuste que descargan sobre él el costo de la política económica, y no determinados requisitos técnicos; se presiona sobre quienes tienen menos capacidad de reacción y defensa.

Pero al mismo tiempo es evidente que el pensamiento crítico latinoamericano, en general, no ha pasado, en el terreno económico, de propuestas genéricas en favor de una amplia estatización de la economía. Buena parte de lo que convencionalmente podemos considerar política económica de orientación socialista en el muindo subdesarrollado, fue simplement una especie de desarrollismo de izqu.erda. El fracaso mayor o menor de es as propuestas, o su agotamiento, han dejado desarmado al pensamiento crítico, y a las organizaciones y fuerzas que se inspiraban en él, frente a los embates renovados del neoliberalismo.

Desde una perspectiva política popular, el problema no es si una política de ajuste es inevitable o no, sino si es inevitable o no que el costo social de las políticas de ajuste recaigan exclusivamente, o ante todo, en el campo popular. El ajuste puede ser inevitable, pero su costo social es producto de decisiones de política y, en definitiva, de una orientación clasista.

Es innegable que hasta el momento las organizaciones populares latinoamericanas han prestado más atención a la denuncia de los efectos negativos del ajuste, o a llorar sobre la leche derramada de las oportunidades perdidas, que a diseñar alternativas. Mas en general, es poco lo que se ha trabajado 


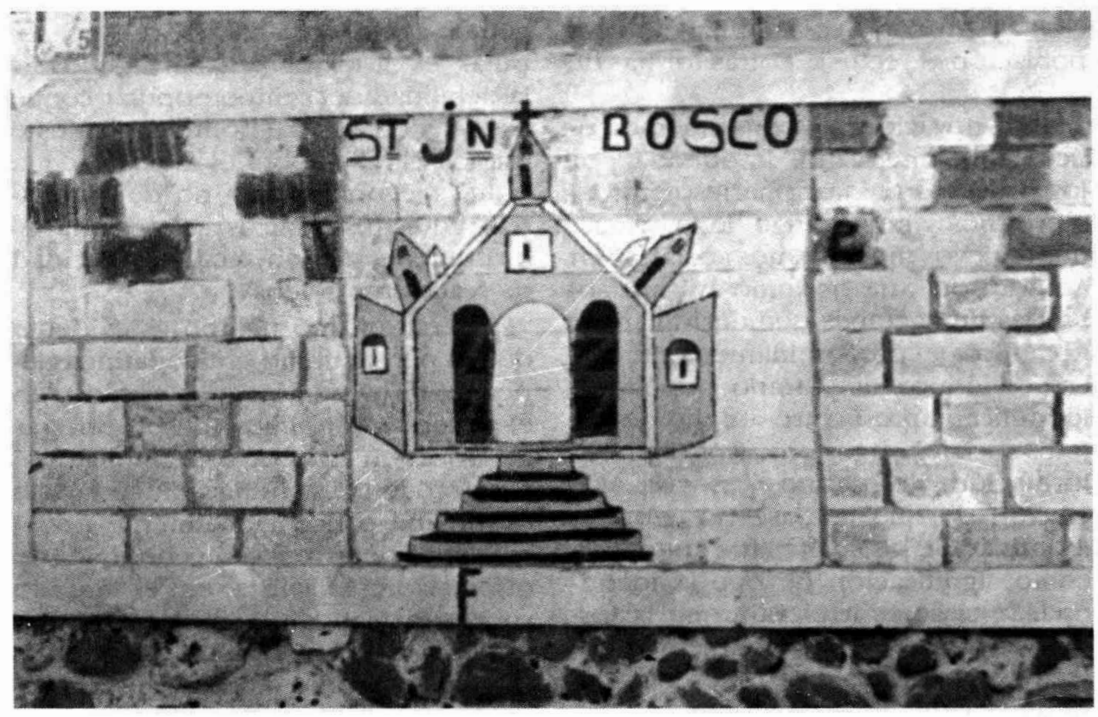

en esos ámbitos en materia de estrategias de desarrollo. La hipótesis de hacer de la satisfacción de las demandas populares de comida, trabajo, salud y educación una estrategia de acumulación y cambio, ha sido considerada sólo esporádicamente por los economistas latinoamericanos vinculados a las organizaciones populares. ${ }^{9}$

Poner énfasis en la respuesta a las demandas básicas de las mayorías populares, y diseñar a partir de esa respuesta una nueva matriz de articulaciones e interconexiones de producción, acumulación, inversión y consumo, no implica necesariamente suscribir una estrategia de "desenganche", u

9 Thomas, Dependence, y Vilas, Transicion. cap. III. "olvidarse" del sector externo, ${ }^{10}$ sino redimensionar el sector externo, y en concreto la capacidad de exportación, a las necesidades de importación ligadas a un reenfoque de la economía a partir de las demandas básicas de las masas populares. Un reenfoque que involucra profundas alteraciones en las relaciones de poder $y$, sin duda, una profunda democratización de la economía y de las políticas y estrategias de desarrollo.

10 Propuestas de "desenganche" como las de Amin, Delinking, 1990, no parecen percibir que lo que recomiendan como estrategia de desarrollo es más bien un efecto de la agresión imperialista a los procesos de liberación nacional y revolución social en el mundo subdesarrollado; cfir. Vilas, "Socialism", 1990, pp. 205-218. 
cambiantes y a aceptar los desafíos de los nuevos tiempos.

La magnitud de la crisis, el peso de la represión que desarticuló a muchas organizaciones populares y eliminó a dirigentes y cuadros, la abdicación de amplios sectores de intelectuales, ponen hoy a las fuerzas populares a la defensiva. La coyuntura actual no es de avance sino, en el mejor de los casos, de recomposición.

La década de 1990 presencia en América Latina el cierre del ciclo de luchas insurreccionales que se abrió tras el triunfo de la revolución cubana en 1959. Pero las condiciones socioeconómicas que detonaron la apertura de dicho ciclo siguen abiertas, y hoy son más apremiantes que entonces. Las democracias eléctorales se muestran más preocupadas por satisfacer a los acreedores externos que a sus propios votantes. De acuerdo a un documento reciente de la Organización Mundial de la Salud, entre 90 y 120000000 de latinoamericanos podrían ser afectados por la presente epidemia de cólera: una tragedia medieval en plena era posmodernista.

Democracia social es el nombre que, a partir del siglo XIX, se dio a las aspiraciones populares a una vida de dignidad, justicia y libertad. Esas aspiraciones no han desaparecido con el muro de Berlín o con las estatuas de Lenin. Pero la profundización de la crisis y las nuevas condiciones internacionales obligan a la búsqueda de nuevas vías, ideas y contenidos. La vitalidad y el arraigo del ideal de justicia, libertad y dignidad radica, ante todo en su capacidad de adaptarse a las realidades

\section{BIBLIOGRAFía}

-Amin, Samir, Delinking, Zed Books, Londres, 1990.

-Aristóteles, Política, Instituto de Estu. dios Políticos, Madrid, 1958.

-Cerroni, Umberto, 11 rapporto uomo. donna nella civiltá borgbese, Ed. Riuniti, Roma, 1976.

-Cooper, Thomas, Lectures on the elements of political economy, Morris \& Wilson, Columbia S.C., 1829.

-Milibiand, Ralph, Divided societies, Oxford University Press, Oxford, 1989.

-Przeworski, Adam, Capitalismo y' socialdemocracia, Alianza Editorial, Madrid, 1988.

-Sampay, Arturo Enrique, Constitución y pueblo, Cuenca Ediciones, Buenos Aires, 1973.

-Smith, Adam, An inquiry into the nature and causes of the wealth of na. tions, The University of Chicago Press, Chicago, 1976 (Investigación sobre la natura. leza y causas de la riqueza de las nacio. nes, Fondo de Cultura Económica, México, 1958).

-Therbon, "The rule of capital and the rise of democracy", New Left Review, núm. 103, mayo-junio 1977, pp. 71-109

-Thomas, Clyve, Dependende and trans. formation, Monthly Review Press, Nueva York, 1974

-Vilas, Carlos, M., Transición desde el subdesarrollo, Nueva Sociedad, Caracas, 1989. native for the Third Wordl?", en William K. Tabb (comp.), The future of socialism. Perspectives from the left, Monthly Review Press, Nueva York, 1990. 


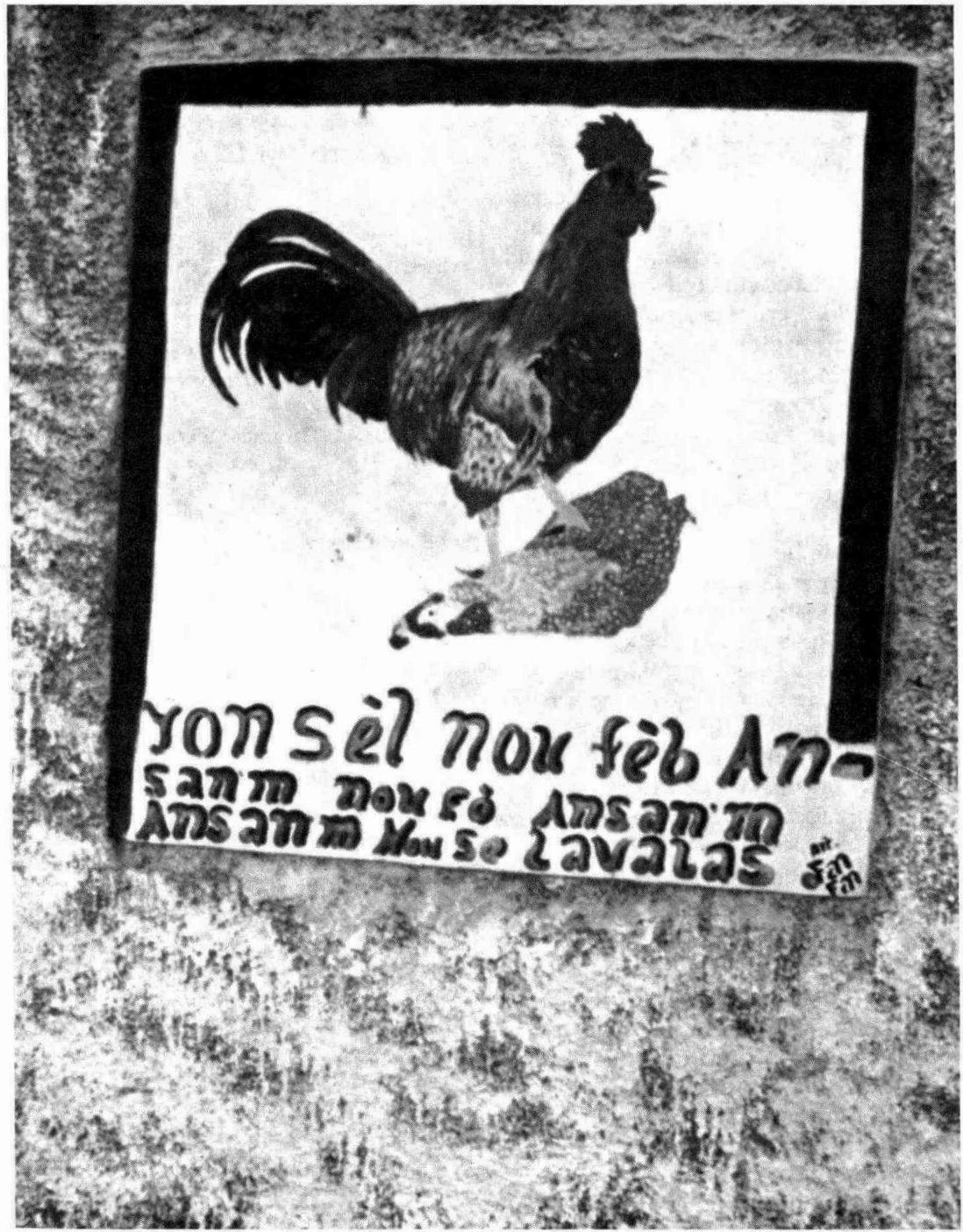

